\title{
250 MHz Multiphase Delay Locked Loop for Low Power Applications
}

\author{
Shruti Suman', K. G. Sharma ${ }^{2}$, P. K. Ghosh ${ }^{3}$ \\ ${ }^{1,3}$ Departement of Electronics and Communication Engineering, College of Engineering and Technology, \\ Mody University of Science and technology, Lakshmangarh, Rajasthan, India \\ ${ }^{2}$ Departement of Electronics and Communication Engineering, Chandigarh College of Engineering and Technology, \\ Chandigarh, India
}

\begin{tabular}{l}
\hline Article Info \\
\hline Article history: \\
Received Mar 17, 2017 \\
Revised Sep 8, 2017 \\
Accepted Sep 20, 2017 \\
\hline Keyword: \\
Delay locked loop \\
Voltage controlled delay line \\
Differential pair configuration \\
Phase frequency detector \\
Charge pump \\
Loop filter
\end{tabular}

\begin{abstract}
Delay locked loop is a critical building block of high speed synchronous circuits. An improved architecture of amixed signaldelay locked loop (DLL) is presented here. In this DLL, delay cell based on single ended differential pair configuration is used for voltage controlled delay line (VCDL) implementation. This delay cell provides a high locking range with less phase noise and jitter due to differential pair configuration.For increasing the acquisition range and locking speed of the DLL, modified true single phase clock (TSPC) based phase frequency detector is used. The proposed design is implemented at 0.18 um CMOS technology and at power supply of $1.8 \mathrm{~V}$. It has power consumption of $1.39 \mathrm{~mW}$ at $125 \mathrm{MHz}$ center frequency with locking range from $0.5 \mathrm{MHz}$ to $250 \mathrm{MHz}$.
\end{abstract}

Copyright () 2017 Institute of Advanced Engineering and Science. All rights reserved.

\section{Corresponding Author:}

Shruti Suman,

Departement of Electronics and Communication Engineering,

College of Engineering and Technology,

Mody University of Science and Technology, Lakshmangarh, Sikar, Rajasthan, India.

Email: shrutisuman23@gmail.com

\section{INTRODUCTION}

In the era of recent development in deep submicron technologies, requires high operating frequency of VLSI systems and subsystems. High speed ICsrequiresproperlysynchronized on-chip clock signals for their operation. For clock synchronization operation in microprocessors and memory ICs, delay locked loop (DLL) and phase locked loop (PLL) are used to diminish the effect of jitter and skews of clock signals [1]. In DLL, VCDL is used in place of VCO which makes it differ from PLL. If frequency multiplier operation is not needed then a DLL is preferred over PLL because of high stability, less locking time and no jitter accumulation [2],[3]. DLL has a wide number of applications such as clock generators in DRAM ICs, microprocessors, clock de-skewing circuits [4],[5]. Locking time, lock range and jitter performance, static phase error, low power consumption and immunity against process voltage temperature loading (PVTL) variations are the most important metrics of a DLL. A DLL can be realized by a number of architectures; analog and digital DLLs are the two most important types among them [6]. Analog DLLs have better performance in terms of jitter, layout area, power supply rejection ratio, power consumption and clock skew.

This paper introduces a mixed mode DLL in which single ended differential pair based VCDL is used which provides high stability against temperature and power supply variations. The proposed circuit depicts superior performance in terms of speed, power consumption, and locking range. The organization of remaning four sections are starting with architecture of basic DLL followed by analysis of different blocks, simulation results and conclusion. 


\section{BASIC DLL}

Delay locked loop (DLL) (block diagram is given in Figure 1) is a negative feedback structure, used to produce multiphase clock signals from a single clock signal [7]. A phase shift is developed at each stage by applying input reference clock signal to voltage controlled delay line (VCDL). The phase difference among reference clock signal and output clock signal is detected by phase detector (PD). For adjustment of control voltage of VCDL, the phase error is used by charge pump (CP) with loop filter. Phase error is finally reduced to zero due to negative feedback mechanism which is the indication of locked state and at that time delay of VCDL becomes equal to one clock period. If $\phi_{\text {in }}$ and $\phi_{\text {out }}$ are input and output clock signals respectively and $t_{V C D L}$ is delay provided by VCDL, the delay provided by DLL can be given by equation (1) as

$$
\phi_{\text {out }}=\phi_{\text {in }}+t_{V C D L}
$$

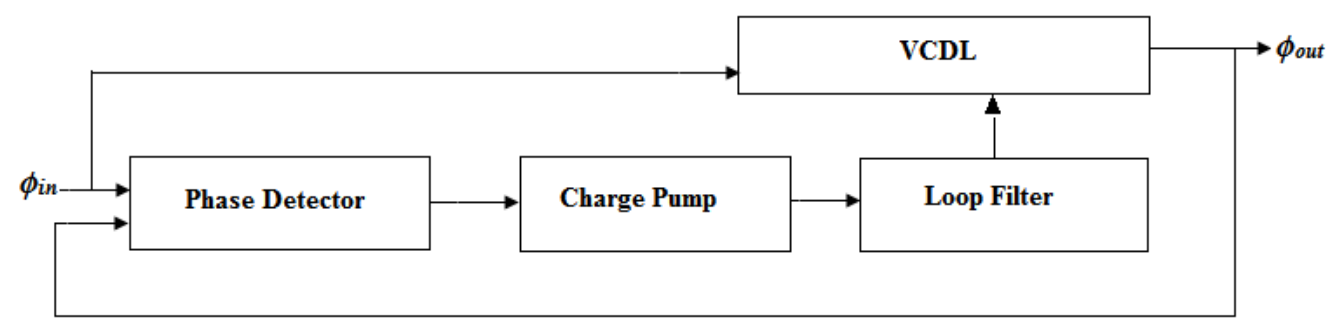

Figure 1. Block diagram of DLL

\subsection{Linear analysis of DLL}

For linear analysis, s-domain model of DLL is shown in Figure 2, which includes transfer function of different blocks.

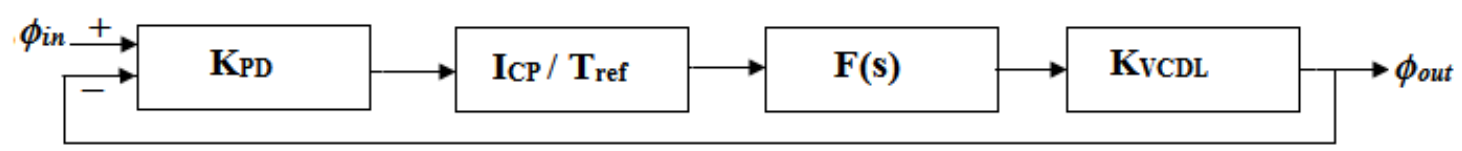

Figure 2. S doman model of DLL

In this model $K_{P D}$ (radian / second) denotes the phase detector gain. $I_{C P}(\mathrm{~A})$ and $F(s)$ are the current through charge pump and loop filter transfer function, respectively. VCDL gain isgiven by $K_{V C D L}$ (radian / V) and it is proportional to number of delay lines. Input clock signal has the period of $T_{\text {ref }}(\mathrm{s})$. For suppressing the jitter amplification over high frequencies, a second order loop filter is used, then $F(s)$ can be given by equation (2) as

$$
F(s)=\frac{R_{1} C_{1} s+1}{\left(R_{1} C_{1} C_{2} s+C_{1}+C_{2}\right) s}
$$

Thus closed loop transfer function of DLL can be specified as

$$
\frac{\phi_{\text {out }}}{\phi_{\text {in }}}(s)=\frac{\frac{I_{P} K_{P D} K_{V C D L}}{T_{r e f}}\left(R_{1} C_{1} s+1\right)}{R_{1} C_{1} C_{2} s^{2}+\left[C_{1}+C_{2}+I_{P} K_{P D} K_{V C D L} R_{1} C_{1} / T_{r e f}\right] s+I_{P} K_{P D} K_{V C D L} / T_{r e f}}
$$




\section{DIFFERENT FUNCTIONAL BLOCKS OF PROPOSED DLL}

The design and analysis of different functional blocks of DLL i.e. phase detector, charge pump with loop filter and VCDL are discussed in the subsequent subsections.

\subsection{Phase frequency detector}

Phase detector is the most critical component of DLL. PD generates the phase error information corresponding to the phase difference between VCDL output clock and ref clock signal. Flip- flop based phase detectors are most commonly used because they have no duty cycle dependence problem due to edge detection [8].

Phase frequency detector (PFD) shown in Figure 3 is implemented using modified TSPC flip-flop. This PFD has high acquisition range and locking speed because it can detect both frequency and phase. When reference ( $r e f)$ and resetsignals are low, in the upper flip-flop, node N1 is charged to VDD through transistors M1 and M2.The output node $U p$ is connected to ground through transistors M5 and M6 at the rising edge of the ref signal. When the reset signal goes high, node N1 is disconnected from VDD by transistor M2 and connected to ground by transistor M3. As soon as the node N1 is discharged, the output node is pulled up through transistor M4 [9],[10].

Signals ( $U p$ and Down) are generated by PFD according to the phase difference between the output signal of VCDL and rising edge of the reference signal. When D input is connected through ground then on the rising edge of the reference signal ref and VCDL output, zero is sent to the flip-flops output $U p$ and Down, correspondingly, which makes the output of NOR gate logic high. As D input of flip-flop is connected to output of NOR gate, as a result the signals ( $U p$ and Down) come again to logic high. When ref signal is greater than $V C D L$, it needs to speed up to pick up; this may leads to add to in the VCDL control voltage which adjusts the VCDL output delay [11].

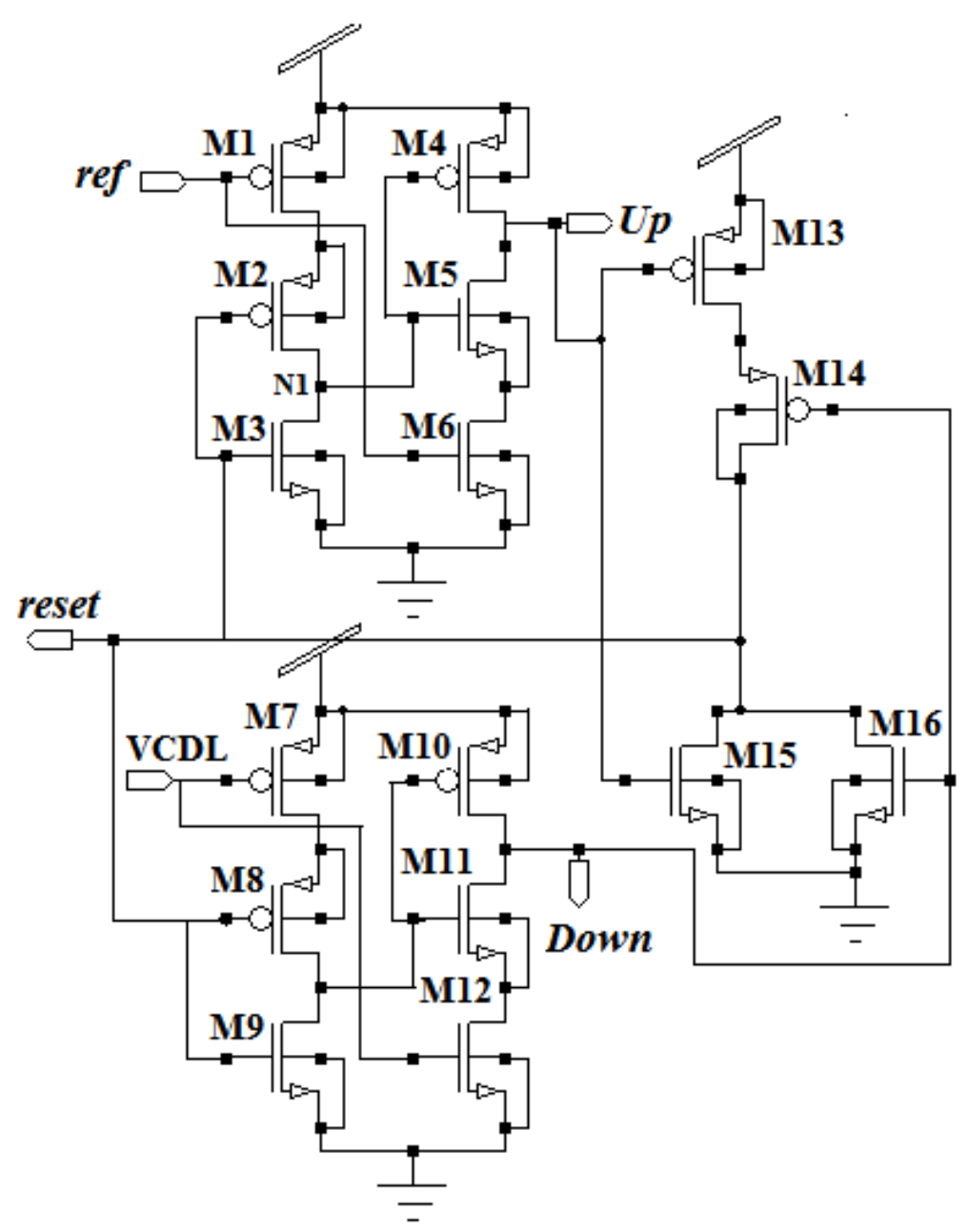

Figure 3. Schematic diagram of phase frequencydetector 
Simulation results of phase frequency detector areshown in Figure 4. Total power dissipation by this phase detector is approximately $0.5196 \mathrm{~mW}$.

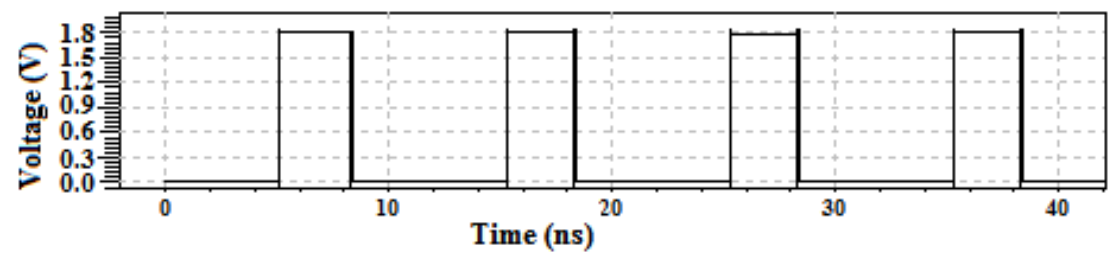

V(Down)

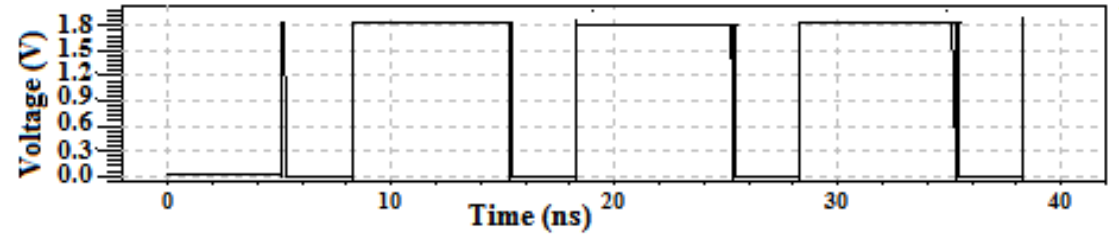

$\mathrm{V}(\mathrm{Up})$

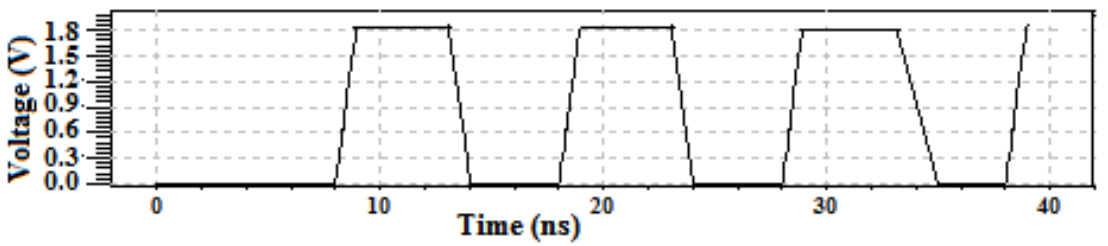

V(VCDL)

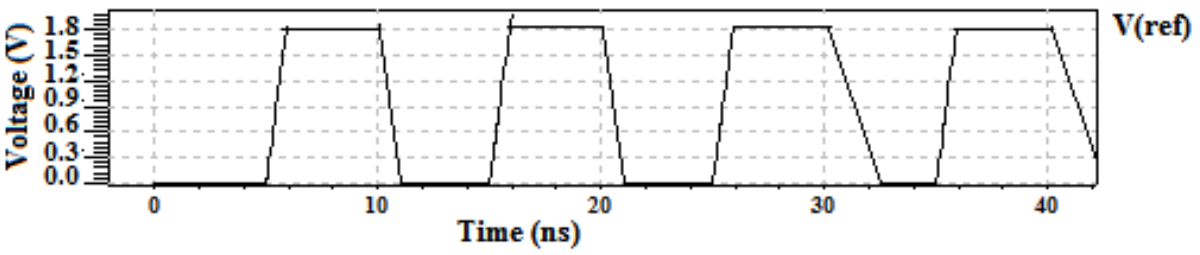

Figure 4. Simulation waveforms of PFD

\subsection{Charge pump in the company of loop filter}

Phase error detected by PFD is transferred to the charge pump in the form of voltage pulses. The CP adjusts the voltage level of loop filter by charging or discharging current and controls the delay of VCDL.

Charge pump which is a bipolar switched current source consists of current source and sink. According to $U p$ and Down signals, output of charge pump is positive and negative current pulses into the loop filter of the DLL. Figure 5 is the schematic of charge pumpalong with loop filter; where transistor M1 and M4 behave as current sourse and sink respectively. Middle transistors M2 and M3 are operated as switches for which gate pulses are provided by PFD outputs [10].

Second ordered loop filter basically used to translate the output signal of PFD to control voltage. It filters out jitter at high frequencies so that jitter peaking effect is reduced. Charging or discharging of the capacitor of the loop filter takes place according to the CP output. When locked state is achieved then output of loop filter is almost constant. The Up and Down input voltages and the output of charge pump along with loop filter is shown in Figure 6 [11],[12]. 


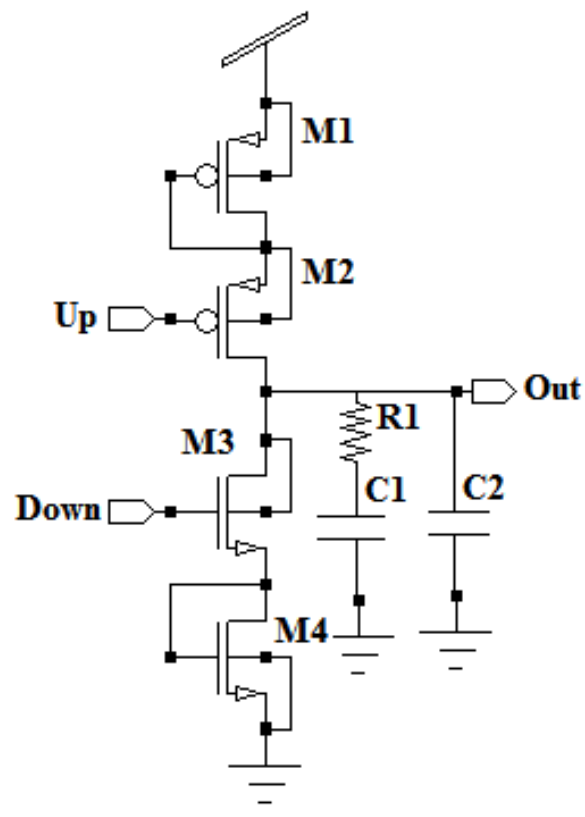

Figure 5. Schematic of charge pump along with loop filter
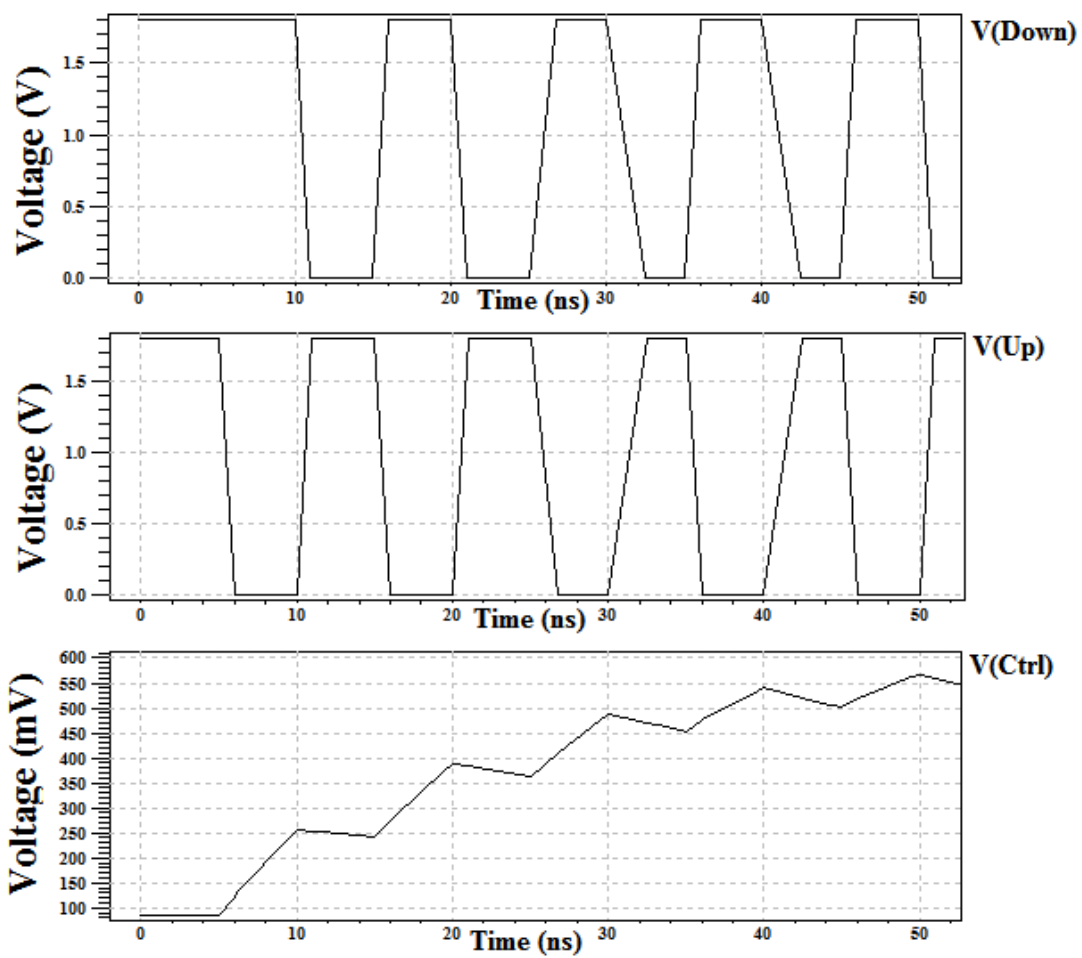

Figure 6. Simulation waveforms of charge pump with loop filter

\subsection{Voltage controlled delay line}

VCDL affects the jitter performance of output clock signal and stability of DLL so it is also a critical block of DLL. In VCDL a number of delay lines are connected in series. In locked state total delay provided by VCDL must be equal to one clock time period $\left(\tau_{\text {ref }}\right)$ or phase shift of $360^{\circ}$. Output swing and delay range are the main design parameters of each delay cell.

Here active load differential pair configuration based delay cell is used for VCDL implementation as shown in Figure 6. It has advantage of both single ended and differential architecture of VCDL delay cell due 
to which PVTL variations are minimized.In this delay cell inverter operation is performed by transistor M4 which is active loaded by transistor M2. Transistor M3 is a diode connected structure which controls the current flow through the transistor M2 by control voltage $\left(V_{c t r l}\right)$ variation. In this delay cell only a single NMOS transistor performs inverting operation instead of CMOS configuration, so less parasitic capacitance is present at output which results delay minimization and high operating speed.

Proposed VCDL which consists of four delay cells is shown in Figure 8. At $0.18 \mu \mathrm{m}$ CMOS technology delay variation with respect to control voltage is graphically presented in Figure 9 which shows that delay is almost constant at low control voltages and after that it decreases. So gain of VCDL ( $\left.K_{V C D L}\right)$ is not so much varied with control voltages due to which DLL output jitter noise is small at larger delays.

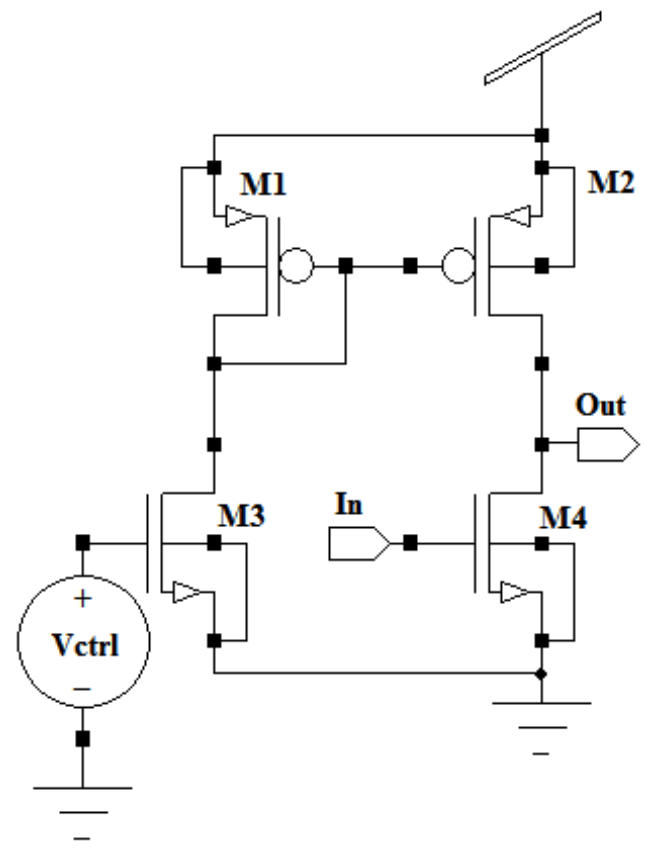

Figure 7. Proposed delay cell

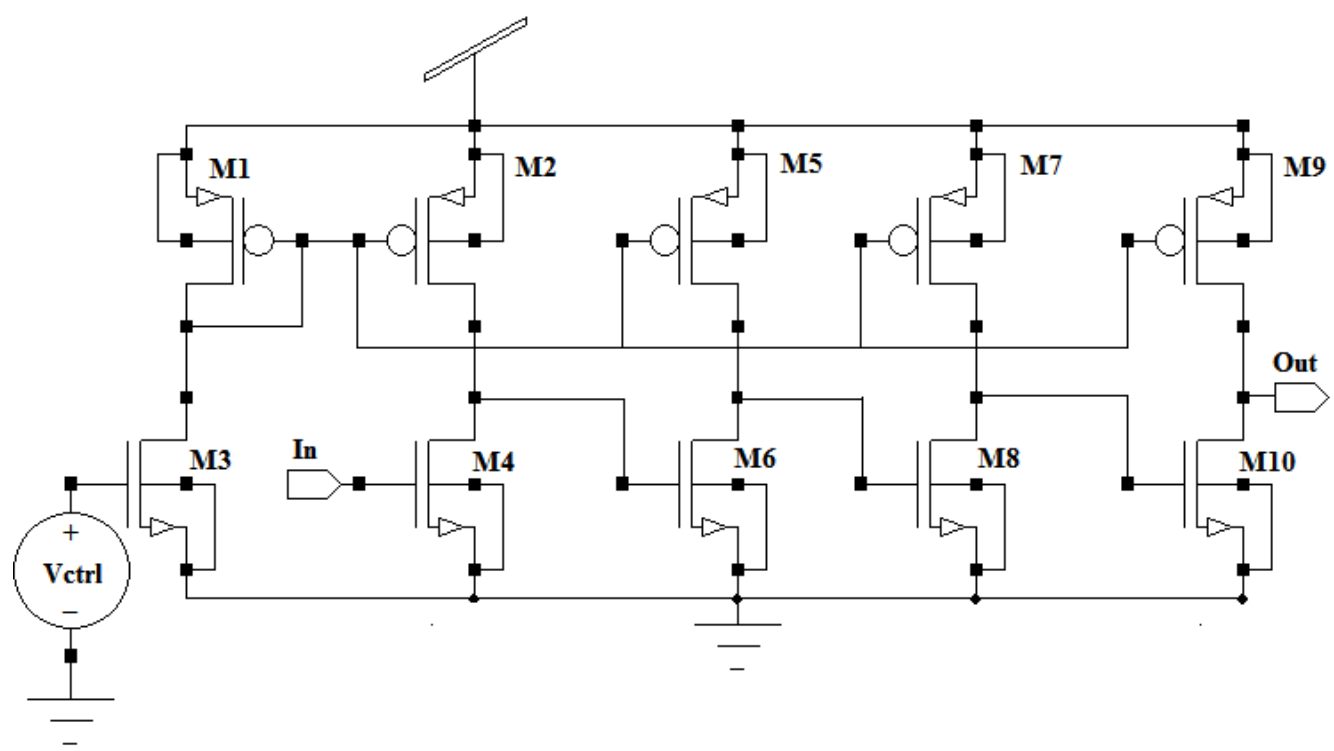

Figure 8. Schematic diagram of four stage VCDL 


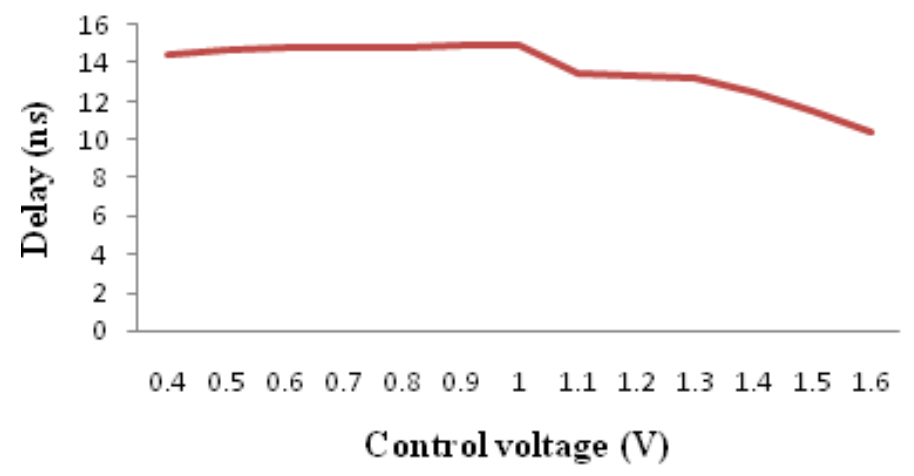

Figure 9. Variation of delay with control voltage (VCDL transfer function)

\section{SIMULATION RESULTS}

Proposed DLL, (Figure 10), is implemented at $1.8 \mathrm{~V}$ supply voltage and $0.18 \mu \mathrm{mCMOS}$ technology.

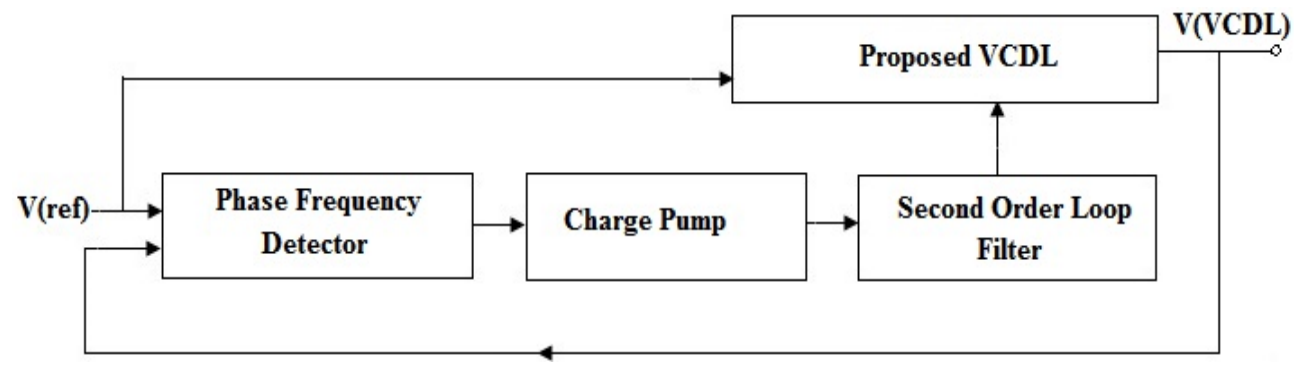

Figure 10. Functional schametic of designed DLL
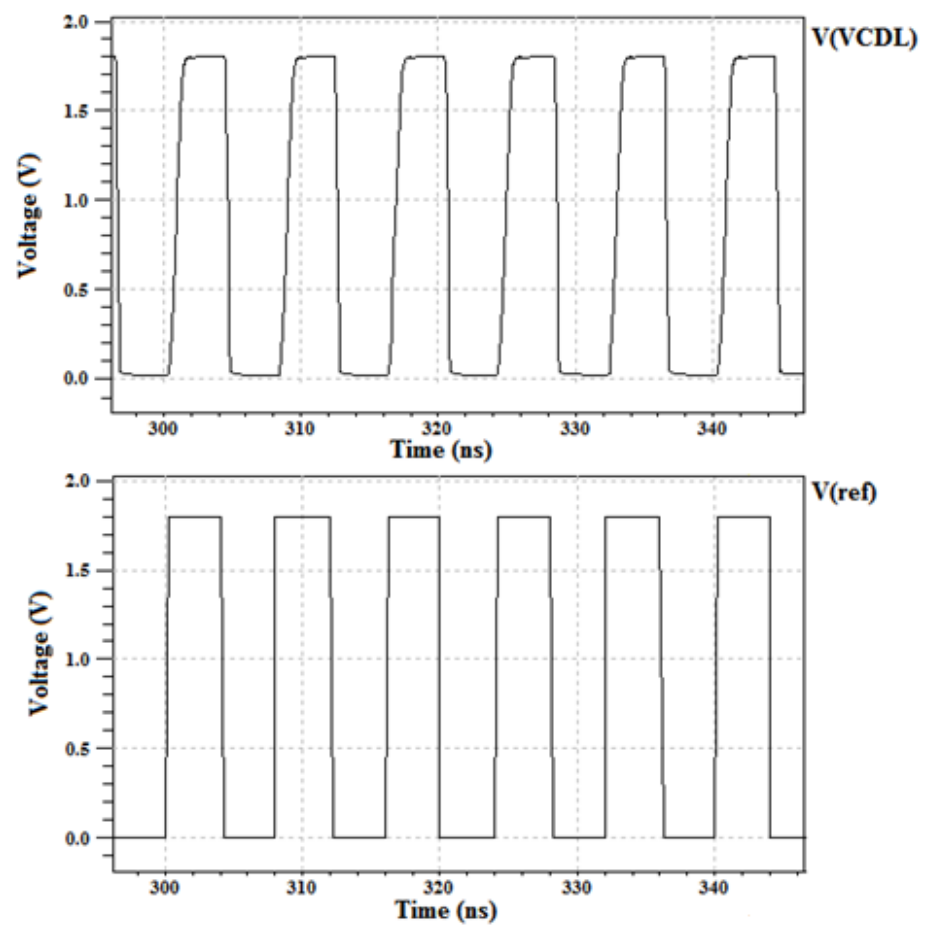

Figure 11. Simulation waveforms of DLL in locked state 
It has high operating speed and a good jitter performance as compared to existing delay cells. Performance specifications of proposed circuit are summarized in Table 1. This DLL has $1.3918 \mathrm{~mW}$ power consumption and $0.52 \mathrm{~ns}$ static phase error at $125 \mathrm{MHz}$ operating frequency. VCDL output clock signal is properly phase aligned with reference clock signalas shown in Figure 11.

Table 1. Specifications of proposed DLL

\begin{tabular}{cc}
\hline Parameters & Values \\
\hline Process technology & $0.18 \mu \mathrm{m}$ CMOS \\
Supply voltage & $1.8 \mathrm{~V}$ \\
Center frequency & $125 \mathrm{MHz}$ \\
Locking range & $0.5 \mathrm{MHz}-250 \mathrm{MHz}$ \\
Power consumption & $1.3918 \mathrm{~mW}$ at $125 \mathrm{MHz}$ \\
Architecture & Single loop \\
\hline
\end{tabular}

The proposed DLL is also simulated at $0.35 \mu \mathrm{m}$ CMOS technology and results are also compared with existing DLL. Comparative analysis of different performance parameters of proposed DLL and Multiphase output delay locked loop [13] is done in Table 2. From the table it can be concluded that proposed DLL has better performance in provisos of locking range and power utilization with similar supply voltage and less complex construction.

Table 2. Comparative analysis ofmultiphase-output delay locked loop [13] and proposed DLL at $0.35 \mu \mathrm{m}$

\begin{tabular}{ccc}
\multicolumn{3}{c}{ CMOS technology with supply voltage of 2V } \\
\hline Parameters & ProposedWork & {$[13]$} \\
\hline Center frequency & $65 \mathrm{MHz}$ & $100 \mathrm{MHz}$ \\
Locking range & $5 \mathrm{MHz}-125 \mathrm{MHz}$ & $85 \mathrm{MHz}-115 \mathrm{MHz}$ \\
Power consumption & $0.590 \mathrm{~mW} @ 100 \mathrm{MHz}$ & $3.4 \mathrm{~mW} @ 100 \mathrm{MHz}$ \\
\hline
\end{tabular}

\section{CONCLUSION}

A high locking range and low power DLL is designed and implemented at $0.18 \mu \mathrm{m}$ CMOS technology (Also designed at $0.35 \mu \mathrm{m}$ CMOS technology but showing better performance at $0.18 \mu \mathrm{m}$ CMOS technology) at which it has total power consumption of $1.3918 \mathrm{~mW}$ with very small locked time. Low power specification makes it useful for devices of longer battery life. Proposed DLL circuit performs a proper clock synchronization operation as output clock signal has negligible phase error from input reference clock signal. Layout of the proposed design can be done further for further post layout results.

\section{REFERENCES}

[1] A. Alvandpour, et al., "A $3.5 \mathrm{GHz} 32 \mathrm{~mW} 150 \mathrm{~nm}$ multiphase clock generator for high-performance microprocessors," IEEE Int. Solid-State Circuits Conf. Dig. Tech, pp. 112-113, 2003.

[2] B. W. Garlepp, et al., "A portable digital DLL for high-speed CMOS interface circuits," IEEE J. Solid-State Circuits, vol/issue: 34(5), pp. 632-644, 1999.

[3] M. J. E. Lee, et al., "Jitter transfer characteristics of delay-locked loops-theories and design techniques," IEEE J. Solid-State Circuits, vol/issue: 38(4), pp. 614-621, 2003.

[4] S. I. Liu, et al., "Low-Power Clock-Deskew Buffer for High-Speed Digital Circuitsc," IEEE J. Solid-State Circuits, vol. 34, pp. 554-558, 1999.

[5] C. Park, et al., "A 512 Mb DDR3 SDRAM prototype with CIO minimization and self-calibration techniques," IEEE J. Solid-State Circuits, vol/issue: 41(4), pp. 831-838, 2006.

[6] B. G. Kim and L. S. Kim, "A $250 \mathrm{MHz}-2 \mathrm{GHz}$ wide-range delay-locked loop," IEEE J. Solid-State Circuits, vol/issue: 40(6), pp. 1310-1321, 2005.

[7] B. Razvi, "Design of Analog CMOS Integrated Circuits," Tata McGraw- Hill, Third edition, pp. 569-571, 2001.

[8] S. Suman, et al., "Analysis and Design of Current Starved Ring VCO," in International Conference on Electrical, Electronics, and Optimization Techniques (ICEEOT), held at D. M. I. College of Engineering, Chennai, IEEE Xplore Digital library, pp. 3222- 3227, 2016.

[9] M. Mansuri, et al., "Fast Frequency Acquisition Phase-Frequency Detectors for GSamples/s Phase-Locked Loops," IEEE J. Solid-State Circuits, vol. 37, pp. 1331-1334, 2002.

[10] B. Goyal, et al., "Design of Charge Pump PLL using Improved Performance Ring VCO," in International Conference on Electrical, Electronics, and Optimization Techniques (ICEEOT) held at D. M. I. College of 
Engineering, Chennai during, IEEE Xplore Digital library, pp. 3254-3258, 2016.

[11] B. Goyal, et al., "Design and Analysis of Improved Ring VCO Based on Differential Pair Configuration" in International Conference on Electrical, Electronics, and Optimization Techniques (ICEEOT), held in D. M. I. College of Engineering, Chennai ISBN: 978-1- 4673-9939- 5,IEEE Xplore Digital library, pp. 3473-3477, 2016.

[12] S. Suman, et al., "Performance Analysis of Voltage Controlled Ring Oscillators," in Proceedings of the International Congress on Information and Communication Technology (ICICT), Advances in Intelligent System., Computing (AISC), vol. 439, pp. 29-38, 2015.

[13] R. C. H. Chang, et al, "A multiphase-output delay locked loop with novel start-controlled phase/frequency detector," IEEE transactions on circuits and systems, regular papers, vol/issue: 55(9), pp. 2483-2490, 2008.

\section{BIOGRAPHIES OF AUTHORS}

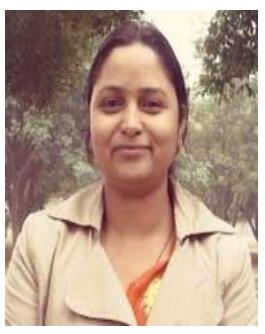

Shruti Suman is pursuing Ph. D. (ECE) from Mody University of Science and Technology, Lakshmangarh, Rajasthan since 2012. She completed her M. Tech. (VLSI Design) in 2012 from Mody Institute of Technology and Science Lakshmangarh, Sikar, Rajasthan, India and B. E. (ECE) from Rajeev Gandhi Technical University, Bhopal, India, in 2010. Her Research Interests are in Analog, Digital and Mixed Signal VLSI Design. Currently she is Assistant Professor in the department of ECE, College of Engineering and Technology, Mody University of Science and Technology, Lakshmangarh, Rajasthan.

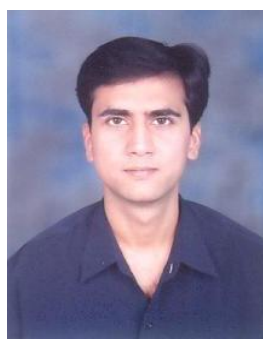

Dr. Krishna Gopal Sharma was born in Kanpur, India in 1977. He received his B.E. degree in Electronics and Communication from Madan Mohan Malviya Engineering College, Gorakhpur in the year 2001. He completed his M.Tech and PhD in Low Power VLSI design in 2009 and 2013 respectively. After graduation, he started working in R\&D department of LML. He served various Institutions, namely, Mody University, Lakshmangarh and Manipal university, jaipur. Presently he is working in Chandigarh College of Engineering Technology, Govt. Institute under UT Administration. He has published more than 50 research papers in reputed journals and conferences. He is life member of ISTE and member of IEEE. His research area is Low Power VLSI design.

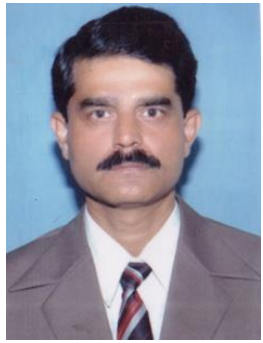

P. K. Ghosh received his B.Sc. (Hons in Physics), B. Tech. and M. Tech. degrees in 1986, 1989, and 1991, respectively, all from Calcutta University. He earned Ph. D. (Tech.) degree in Radio Physics and Electronics in 1997 from the same University. He served various institutions, namely, National Institute of Science and Technology (Orissa), St. Xavier's College (Kolkata), Murshidabad College of Engineering and Technology (West Bengal), R. D. Engineering College (Uttar Pradesh) and Kalyani Government Engineering College (West Bengal) before he joins Mody University of Science and Technology (Rajasthan). To his credit, he has more than 80 research papers in Journals of repute and conference proceedings. He is a life member of Indian Society for Technical Education (ISTE), New Delhi. His research interests are in the areas of VLSI circuits \& devices, wireless communications and signal processing. 